\title{
HIPERCORREÇÕES NA ESCRITA COMO EVIDÊNCIA DA GRAMÁTICA FONOLÓGICA DA CRIANÇA
}

\author{
HYPERCORRECTIONS IN WRITING AS EVIDENCE OF THE CHILD \\ PHONOLOGICAL GRAMMAR
}

Graziela Pigatto Bohn | Lattes | grazielabohn@gmail.com
Mariana de Lima Souza | Lattes | marii_snish@hotmail.com Universidade Católica de Santos

\begin{abstract}
Resumo: O trabalho apresenta uma análise da escrita inicial, buscando identificar evidências da influência de processos fonológicos do português brasileiro no processo de aquisição do código escrito. $\mathrm{O}$ foco do trabalho é identificar, na escrita das crianças, indícios de hipercorreção baseada em três fenômenos fonológicos presentes na fala: a harmonia vocálica, o alçamento vocálico e a semivocalização da líquida lateral em posição pós-vocálica. O trabalho parte da seguinte questão: será que no momento em que a criança se depara com o código escrito e percebe que as letras nem sempre apresentam uma relação direta com a forma como são pronunciadas (ou seja, um 'i’ falado nem sempre será um 'i’ na escrita), além de corrigir seus erros ortográficos iniciais, elas passam a hipercorrigir suas produções escritas? Além disso, o trabalho busca evidências empíricas de como a gramática fonológica da criança atua na aquisição da escrita ao se esperar que as hipercorreções sejam regidas por restrições da fonologia da língua. A fim de abordarmos essas questões, analisamos dados de escrita inicial de um banco de dados organizado pelo Projeto Aspa da Universidade Federal de Minas Gerais, o E-labore (Laboratório Eletrônico de Oralidade e Escrita) (CRISTÓFARO-SILVA et al., 2009). Os resultados nos mostram que há, sim, hipercorreções relacionadas aos processos fonológicos da língua na aquisição do código escrito e que estas são majoritariamente regidas por restrições fonológicas do português brasileiro.
\end{abstract}

Palavras-chave: Fonologia; Aquisição da escrita; Consciência fonológica. 
Abstract: This paper examines the influence of the phonological grammar in the acquisition of written Brazilian Portuguese. Our focus is to identify children's hypercorrections based on three phonological phenomena: vowel harmony, vowel raising and post-vocalic l-vocalization. The work is based on the following prediction: at the moment the child is confronted with the written language and realizes that letters do not always correspond to phonemes, in addition to correcting his/her initial orthographic errors, he/she is also expected to overgeneralize his/her corrections to unnecessary written forms. This study also seeks to find empirical evidence that shows how active a child's phonological grammar is in the acquisition of writing since it is expected that these hypercorretions are governed by phonological restrictions of the language. In order to address these issues, we analyzed initial writing data from a database organized by the Aspa Project of the Federal University of Minas Gerais, E-labore (Electronic Laboratory of Orality and Writing) (CRISTÓFARO-SILVA et al., 2009). The results show that there are, indeed, hypercorretions related to phonological processes in the acquisition of written Brazilian Portuguese and that these are mainly governed by phonological restrictions of the language.

Keywords: Phonology; Acquisition of writing; Phonological awareness.

\section{Introdução}

Dados de escrita inicial têm-nos cada vez mais mostrado a importância de entendermos as relações que a criança estabelece com a fala quando passa a aprender o código escrito da língua. Segundo Miranda e Cunha (2013), considerando as especificidades dos processos de aquisição, a linguagem oral é desenvolvida espontaneamente pela criança, em um período relativamente curto, sem que seja necessária uma instrução. A criança constrói sua fonologia com mecanismos externos e internos, desde antes do nascimento até o fim da primeira infância, por volta dos quatro ou cinco anos de idade (cf. LAMPRECHT, 2004).

Já a aprendizagem da escrita depende de um auxílio direto e, para alcançar o domínio desse código, é necessário que a criança compreenda de que forma as letras se relacionam com os sons da língua - uma relação nem sempre direta. Isso porque mais de uma letra pode ser usada para representar um som (como é o caso do fonema $/ z /$ sendo representado pela letra ' $z$ ' em azar, 's' em casar ou ' $x$ ' em exame) ou vice-versa, isto é, diversos fones sendo representados pela mesma letra (como é o caso da grafia 'r' que pode ser realizada na fala como [г], [х], [б] ou [h], em coda silábica, a depender do dialeto e do 
contexto linguístico). Esses fatos por si só já indicam a distância que pode existir entre a fala e a escrita (LEMLE, 1987). E é justamente a tentativa de se estabelecer uma relação direta e biunívoca entre os sons e as letras, tanto por parte do educador quanto por parte da criança, que implicará a ocorrência de obstáculos no processo de alfabetização (SILVA, 2016).

Lemle (1987) mostra-nos que, no português brasileiro (PB), os casos de correspondência biunívoca são, na verdade, minoria - há apenas sete casos em que há uma relação direta e única entre som e letra: b, p, t, d ${ }^{1}$, f, v, a. Os outros casos são poligâmicos, e é em relação a eles que devemos evitar estabelecer a relação direta.

A falta de consciência metalinguística pode levar o educador a insistir em correspondências inexistentes - insistir, por exemplo, que os sons finais das palavras 'pato' e 'papel' são, respectivamente, [o] e [1] quando a criança, na verdade, os produz como [U] e [w] - ['pa.tu] e [pa'pew]. Trata-se de fenômenos fonológicos já adquiridos pela criança durante o processo de aquisição oral, o primeiro consistindo na neutralização vocálica e o segundo na regra de semivocalização do /1/, facilmente transferidos para a escrita inicial: 'patu' e 'papeu'. Uma vez descoberta a relação não biunívoca existente entre sons e letras, espera-se que a criança passe a corrigir seus próprios erros ortográficos: 'patu' vira 'pato' e 'papeu' vira 'papel'.

Neste artigo, entretanto, interessa-nos ir além dessa descoberta e dessas correções. Nosso propósito é focar nas hipercorreções. Com isso, buscamos investigar com dados empíricos se, além de corrigir em contextos certos, a criança também transfere a correção para contextos que não precisariam de reparo. Ou seja, ao se dar conta de que o [u] final de [patu] e o [w] final de [papew] são, na verdade, um 'o' e um 'l' na forma escrita, a criança poderia criar a hipótese de que todo $[\mathrm{U}]$ e $[\mathrm{w}]$ produzidos nesses contextos devem ser grafados com 'o' e ' 1 ', respectivamente, produzindo formas escritas como 'cajo' para 'caju' e 'acordou' para 'acordou', por exemplo. E, com base nas condições que regem as hipercorreções encontradas, buscaremos evidências empíricas da gramática fonológica da criança operando na aquisição do código escrito.

\section{Escrita e consciência fonológica na alfabetização}

Ao ser apresentada ao código escrito, é natural que a criança estabeleça relações com o seu conhecimento linguístico previamente adquirido. E por ser a escrita um código convencionado que representa graficamente os sons da fala, é natural que essas rela-

\footnotetext{
${ }^{1}$ Deve-se lembrar aqui, entretanto, que os fonemas /d/ e/t/ podem ainda sofrer palatalização na fala quando precedem uma vogal coronal e alta, como é o caso de /dia/ e /tia/ que podem ser realizadas como [dzia] e [ $\mathrm{t} \mathrm{i} \mathrm{a}]$, respectivamente.
} 
ções sejam estabelecidas, em especial, com a sua gramática fonológica.

Entretanto, como vimos na seção que inicia este artigo, essas relações nem sempre são diretas, o que leva a criança a cometer deslizes ortográficos, muitas vezes referidos como 'erros' ortográficos, cujas motivações vão além de simples trocas arbitrárias de letras.

Apesar de muitas vezes a criança deixar-se levar pela forma como pronuncia as palavras, para Abaurre (1999, p. 172) é preciso que fiquemos atentos à ideia ingênua de que a escrita inicial é uma reprodução fiel da oralidade, o que, segundo a autora, implicaria uma dependência radical da escrita à fala. Observe que esse seria o caso de escritas como pérula e posti, para 'pérola' e 'poste', respectivamente (dados retirados de LEMOS, 2001), mas o apoio total na oralidade não explicaria casos como escevo e birnco, conforme exemplifica Abaurre (1999, p. 177). Para a autora, dados como esses últimos costumam ser tratados como meros lapsos ortográficos, trocas de letras, quando, na verdade, são indícios de uma atividade muito mais complexa e elaborada por parte da criança. Enquanto o primeiro poderia, de fato, ser a reprodução na escrita de uma pronúncia sem o fonema $/ \mathrm{r} /$ no ataque complexo/kre/ (es.cre.vo), o mesmo não poderia ser dito em relação ao segundo. Não se pode imaginar, segundo a autora, que uma criança produza o verbo 'brincar' na primeira pessoa do presente do indicativo como [birnco], mesmo porque ela estaria violando restrições fonotáticas do português brasileiro. Abaurre (1999) levanta a hipótese, então, de que dados de grafia como o birnco acima são reflexo de como a criança elabora, a partir da grafia das palavras, uma análise da estrutura silábica da língua. Isso porque, da mesma forma que na aquisição oral, na aquisição da escrita a criança parece dominar primeiramente a estrutura silábica canônica $\mathrm{CV}$, como em sa.po e bo.ne.ca.

O problema encontra-se, entretanto, em estruturas mais complexas, como é o caso das sílabas CCV e VCC, com ataque e coda complexas respectivamente. Produções escritas do tipo suto ('susto'), gadi ('grande') e seper ('sempre'), entre outras, são indícios dessa dificuldade (ABAURRE, 1999, p. 175-6). Para a autora, portanto, omissões e trocas desse tipo não podem ser interpretadas como reflexo da pronúncia da criança, mas sim como indício de que a criança está, neste momento, apoiando-se na escrita como uma ferramenta para analisar a própria estrutura silábica da língua - o PB licencia ataques e codas complexas, mas essas estruturas são adquiridas mais tarde na aquisição da fonologia da língua.

Da mesma forma, na aprendizagem da escrita, o preenchimento da coda (sus.to) e da segunda posição dos ataques complexos (gran.de, sem.pre) também parecem ocorrer 
mais tarde. A importância de análises como a de Abaurre (1999) é justamente a de sistematizar os lapsos da escrita inicial das crianças, apontando a naturalidade e motivação deles.

Produções como essas servem como valiosas pistas de como a criança se apoia não só na forma como pronuncia as palavras, mas também no seu próprio conhecimento fonológico da língua, como já apontava Ferreiro e Teberosky (1999 [1984]).

Dados de hipo e hipersegmentações das palavras, ou seja, a ausência ou inserção de espaço entre as palavras grafadas, também são indícios do conhecimento fonológico da criança. Por ser a fala um contínuo de constituintes prosódicos, tais como palavra fonológica, frase fonológica e frase entoacional (cf. NESPOR; VOGEL, 1986), é possível que na escrita inicial a criança relacione a grafia das palavras com alguns desses grupos. Cunha (2004) mostra que a criança hipossegmenta desde o nível mais baixo da hierarquia prosódica, unindo uma palavra lexical a uma palavra gramatical (medeu para 'me deu', osgatos para 'os gatos' e chamase para 'chama-se') até níveis mais altos, como a frase fonológica (ubelodia para 'um belo dia' e tãongrande para 'tão grande').

Os dados de Cunha também mostram que a criança pode passar a segmentar estruturas que deveriam estar unidas, ou seja, a hipersegmentar, como tentativa de superar esse estágio: da quela para 'daquela', em bora para 'embora' e na mora para 'namora'. Para Miranda e Cunha (2013), a hipersegmentação também é indício de reflexões sobre a fonologia da língua, e mesmo ela não é aleatória. Observe, conforme aponta Cunha (2004), que as hipersegmentações apresentadas acima deixam à direita uma palavra dissílaba paroxítona, preservando tanto o pé métrico binário, nesses casos um troqueu silábico, quanto as estruturas silábicas. Ou seja, a criança não fere nenhuma restrição prosódica da língua ao hipersegmentar. Além disso, em muitos desses dados, a partícula segmentada assemelha-se a um clítico da língua ( $d a, e m$ e na, nos casos acima). Ou seja, mesmo no erro e nas hipercorreções, a criança apoia-se na estrutura fonológica da língua.

No nível segmental, também encontramos evidências desse tipo. Lemos (2001) examina a grafia das vogais 'e' e 'o' em posição pretônica e conclui que o alçamento dessas vogais para [i] e [u] na fala interfere na escrita: tisoura, minino, bússula, por exemplo. Já em relação à posição pós-tônica final, o autor observa que há maior regularidade. Podemos aventar aqui a possibilidade de a posição pretônica ser mais instável, ora produz-se a pretônica como alta [i] e [u] (qu[i]rido, c[u]ruja), ora como média-alta [e] e [o] (t $[\mathrm{e}]$ cido, $\mathrm{t}[\mathrm{o}]$ rcida) e ora como média-baixa $[\varepsilon]$ e $[\mathrm{o}](\mathrm{r}[\varepsilon]$ lógio, $\mathrm{b}[\mathrm{o}]$ neca), a depender do contexto linguístico e do dialeto, e, por isso, essa posição é menos suscetível a ser sistematizada por 
uma regra que auxilie a grafia correspondente da vogal. A posição pós-tônica final, por sua vez, é mais estável, pois, independentemente do contexto ou dialeto, o /e/ e /o/ subjacentes nesta posição são majoritariamente realizados como [i] e [u], respectivamente (que$\operatorname{rid}[\mathrm{u}]$, tecid[u], lev[i], quas[i], etc.). Nesse sentido, a criança parece estar mais sensível à instabilidade da pauta pretônica na aprendizagem do código escrito e, por outro lado, consegue regularizar mais facilmente a pauta pós-tônica final. Lemos prevê, entretanto, que essa regularidade da pauta pós-tônica final poderá resultar em hipercorreções em palavras que são de fato grafadas com a vogal alta, como é o caso de 'safári' e 'tatu', mas não chega a analisar tais dados.

Greco (2009) também analisa a influência do alçamento da pretônica na aprendizagem da escrita e verifica que, em relação a esse fenômeno, ocorre um efeito retroalimentador da escrita na fala. Seus resultados mostram que há, de fato, maior índice de alçamento nesse contexto tanto na oralidade como na escrita na $1^{\text {a }}$ série, mas, à medida que a criança entra em contato com o código escrito, a autora observa um decréscimo de alçamento na fala e na escrita, em especial na $3^{\text {a }}$ série. É só a partir da $5^{\text {a }}$ série que a criança volta a pronunciar as palavras com o alçamento pretônico da forma como fazia antes, sendo que na escrita a grafia das vogais alçadas continua a diminuir. Cristófaro-Silva e Guimarães (2010) fazem uma predição em relação aos dados de Greco: uma vez que a não-relação é detectada, isto é, um [i] e [u] fonético é grafado como 'e' e 'o' em grande parte das palavras, é possível que as crianças estendam essa regra para palavras que são, de fato, grafadas com as letras 'i' e 'u' em posição pretônica, e, devido ao efeito retroalimentador, passem a pronunciar essas palavras com as vogais [e] e [o] respectivamente. Seria o caso de palavras como 'privilégio' e 'meritíssimo' que passam a ser grafadas como previlégio e meretíssimo e pronunciadas como pr[e]vilégio e mer[e]tíssimo. Para essas autoras, há uma relação de duas vias entre a escrita e a fala na aquisição do código escrito, pois, ao mesmo tempo em que a consciência dos fatos linguísticos pode auxiliar a aquisição do código escrito, esse também pode acabar interferindo no conhecimento linguístico da criança.

Um último trabalho que se faz pertinente mencionar é a investigação da representação gráfica dos ditongos decrescentes do PB conduzida por Adamoli (2010). Com base em seus resultados, Adamoli (2010) também defende que a criança cria suas hipóteses em relação à escrita com base no que ela já adquiriu sobre a fonologia da língua. As reduções dos ditongos [ow], [ej] e [aj], apesar de sofrerem restrições diferentes, são comuns na fala dos falantes do português brasileiro e acabam sendo levadas para a escrita inicial ( $p e-$ che para 'peixe', cacha para 'caixa'). Em um estágio seguinte, a criança passa a produzir for- 
mas flutuantes, ora grafando o ditongo e ora não o grafando. Mas mais interessante ainda é outro fato observado por Adamoli (2010): a inserção da vogal 'i’ em contextos em que não há o ditongo. Esses são casos como peicharão para 'pecharão' e feixar para 'fechar'. A inserção de um ditongo graficamente em um contexto errado é, para Adamoli (2010), uma evidência de consciência metalinguística, pois indica que as crianças já reconhecem os contextos fonológicos em que os ditongos decrescentes são possíveis de configurarem na língua (em contexto que antecede as palatais / / e /Z/, como é o caso de rap[aif] e d[ejS] para 'rapaz' e 'dez' em alguns dialetos do português brasileiro (BISOL, 1994). Além disso, Adamoli (2010) aventa a possibilidade de, uma vez que a criança entende que os ditongos não são realizados na fala mas devem ser grafados na escrita, ela acaba estendendo a regra para contextos em que não há ditongos. Este é o caso específico do ditongo [ow], praticamente não mais produzido como ditongo pela maioria dos falantes $(c[0]$ ro para 'couro' e acab[o] para 'acabou', por exemplo). A descoberta de que o [o] falado é por vezes um 'ou' gráfico pode levar a criança a estender essa grafia para outros [o] fonéticos (boutar para 'botar' e goustar para 'gostar').

Esperamos ter mostrado com esses trabalhos que, tanto nos deslizes ortográficos quanto nas hipercorreções, a escrita inicial da criança é fortemente guiada não só pela forma fonética das palavras, mas também pela sua bagagem linguística, mais especificamente sua gramática fonológica. Nesse trabalho, interessa-nos analisar mais profundamente dados de hipercorreção da escrita a fim de verificar se a criança estende as regras linguísticas para outros contextos, o que pode ser tanto um indício do uso que faz da sua consciência metalinguística quanto de aprendizagem. Para tanto, analisaremos três fenômenos fonológicos do português brasileiro, os quais serão brevemente descritos na seção que segue.

\section{Alguns processos fonológicos do português brasileiro}

\subsection{Harmonização Vocálica}

A harmonização vocálica do português brasileiro é uma assimilação variável do traço alto da vogal/i/ ou /u/ por parte de uma vogal média /e/ ou /o/ em sílaba pretônica precedente (BISOL, 1981; SCHWINDT, 1995; CASAGRANDE, 2004). Variável porque o processo pode não se aplicar em todas as palavras que oferecem o contexto, dependendo de falante para falante ou região para região. No entanto, algumas palavras parecem ser afetadas pela harmonização vocálica quase que por todos os falantes do português brasileiro. São casos como o da palavra 'menino', produzido como [mininu]

Para entender melhor a harmonização vocálica, voltamo-nos à Câmara Jr. (1999

\footnotetext{
${ }^{2} \mathrm{Na}$ fala dos gaúchos, o verbo 'pechar' pode significar 'colidir'.
} 
[1972], p. 43) para quem as vogais do português brasileiro podem ser explicadas através de um triângulo de contrastes vocálicos. Na base do triângulo, encontramos a vogal /a/, a mais baixa de todas. No topo, as vogais /i/ e /u/, as mais altas. No meio, perto do topo, /e/ e /o/, denominadas médias ou médias-altas, e perto da base, $/ \varepsilon /$ e / $/$, as médias-baixas. Seguindo o esquema de Mattoso, podemos notar as diferenças de elevação da língua de acordo com cada vogal pronunciada: /a/ com a língua mais abaixada e /i/e /u/com a língua mais elevada, e no meio /e/ e /o/ com a língua mais elevada do que / $/$ / e / $/$. Podemos ver a disposição das vogais na representação proposta por Câmara Jr. (1999 [1972], p. 44) a seguir:

Figura 1. Sistema vocálico do PB

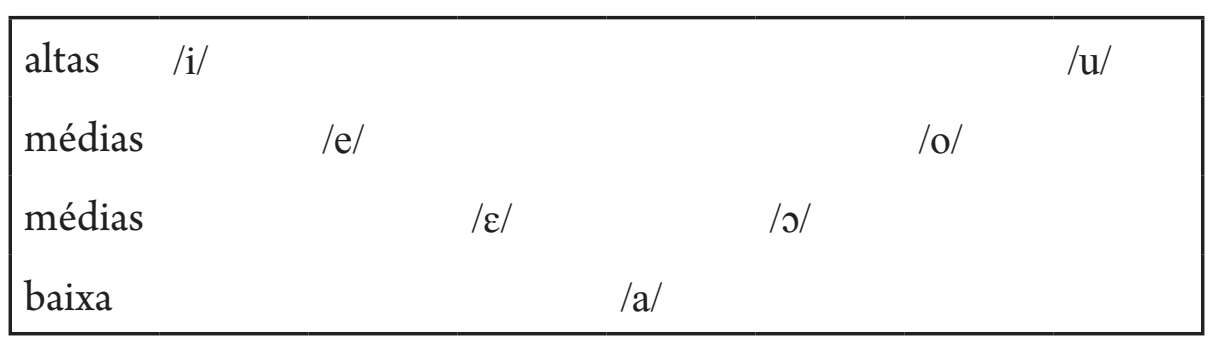

Fonte: Câmara Jr. (1999 [1972], p. 44).

Apesar de opcional, estudos do português brasileiro têm mostrado que a harmonização vocálica da língua tende a obedecer algumas condições linguísticas. Por exemplo, é mais normal harmonizarmos quando a vogal pretônica e a vogal alta estiverem em sílabas adjacentes. Uma palavra como 'metida' é harmonizada para [mitida], mas o/e/ de 'gelatina' não sofre harmonia com a vogal alta $\left({ }^{*}[\text { zilatina }]\right)^{3}$. Outra condição é a vogal /i/ ou /u/ estar dentro do radical da palavra, e não em certos sufixos, como - $(z)$ inho ou - $(z)$ inha. Por exemplo, 'bolinha' não é produzida como [bulina $]^{4}$, pois a vogal alta está em um sufixo que não se une à palavra, tendo entre o radical e o sufixo uma fronteira morfológica. Da mesma forma, a palavra 'medinho' não é produzida como [midino], pois existe nessa palavra um sufixo diminutivo.

Outro aspecto em relação à harmonização vocálica do português brasileiro é o fato de ela ser parcial, e não total. Em algumas línguas, quando a harmonização é total, há a cópia de todas as características da vogal. Se no português a cópia fosse total, teríamos

\footnotetext{
${ }^{3} \mathrm{O}$ asterisco indica agramaticalidade.

${ }^{4} \mathrm{O}$ alçamento de /o/ para [u] pode ser esperado, entretanto, em contextos em que a vogal faz vizinhança com uma consoante labial ou velar, como é o caso de [bu]neca para 'boneca' e [ku]légio para 'colégio'. Diante disso, não podemos descartar completamente a forma alçada [bulina] para 'bolinha'.
} 
produções como [nunuma] para 'nenhuma' e [gazilina] para 'gasolina', nas quais a pretônica copiaria todos os traços da vogal alta.

\subsection{Alçamento Vocálico}

Segundo Monaretto (2013, p. 20), existem três casos de alçamento de vogais médias-altas /e/ e /o/ para [i] e [u] em sílaba pretônica. O primeiro é a harmonização vocálica, abordada na seção anterior; o segundo é o que afeta a vogal/e/ seguida de sibilante ou nasal, como em 'espada' e 'enxada', realizadas como [ispada] e [ĩ̃ada]; e o terceiro é quando a pretônica alça sem sofrer harmonização vocálica ou sem estar seguida de sibilante ou nasal, como é o caso de 'tomate' realizado como [tumate] e 'pequeno' como [pikeno]. Por não se encaixar na harmonização vocálica, um processo fonológico, nem ter uma influência da sibilante ou nasal, um processo fonético, esse terceiro caso é chamado de alçamento sem motivação aparente.

O alçamento sem motivação aparente pode ocorrer em diversos contextos, como em início de palavra ([e]gocêntrico [i]gocêntrico); no interior de palavra (tecn[o]logia $\sim$ tecn[u]logia, $\mathrm{s}[\mathrm{e}]$ nhora $\sim \mathrm{s}[\mathrm{i}]$ nhora); em hiato (t[e]atro $\sim \mathrm{t}[\mathrm{i}]$ atro); em sílaba pesada (p[o]r.ção p[u]r.ção) e em sílaba leve (b[o].neca b[u].neca) (MONARETTO, 2013, p. 21). A autora também mostra que os contextos fonológicos também são analisados, e postula que as consoantes dorsais $(/ \mathrm{k} / \mathrm{e} / \mathrm{g} / \mathrm{e}$ as labiais $(/ \mathrm{p} /, / \mathrm{b} /, / \mathrm{m} /)$, quando antecedem a vogal, e as palatais $(/ \mathrm{n} / \mathrm{e} / \mathrm{K} /)$, quando seguem as vogais, colaboram para que haja o alçamento (como em g[o]verno $\sim \mathrm{g}[\mathrm{u}]$ verno, $\underline{\mathrm{m}}[\mathrm{e}] \underline{\mathrm{h}}$ or $\sim \underline{\mathrm{m}}[\mathrm{i}] \underline{\mathrm{hhor}}$ ).

Da mesma forma que a harmonização vocálica, o alçamento sem motivação aparente também é um processo variável do português brasileiro, dependendo do falante. Por exemplo, a produção [tumate] para 'tomate' não é comum em diversas regiões do Brasil, mas ocorre em regiões como a de Minas Gerais.

\subsection{Semivocalização da líquida lateral em posição pós-vocálica}

A semivocalização da líquida lateral em posição pós-vocálica é um processo fonológico do português brasileiro no qual a consoante /1/ é produzida com a vogal [U] ou com a semivogal [w]. De acordo com Battisti e Moras (2016, p. 91), o processo pode afetar a consoante tanto em coda medial (como em a[1]moço $\sim \mathrm{a}[\mathrm{w}]$ moço, fa[1]ta $\sim \mathrm{fa}[\mathrm{w}] \mathrm{ta}$ ) como em coda final (futebol[1] futebol[w], móve[1] móve[w]).

Entretanto, pronúncias como em 'fa[1]ta' em que a lateral é produzida como uma lateral velarizada / $/$ / são raras no português brasileiro, permanecendo na fala de pessoas 
mais idosas e do sul do país. Para Battisti e Moras (2016, p. 92), é mais comum encontrarmos a semivocalização. Para Pinho e Margotti (2010), o português brasileiro tende, em muito breve, a adotar a realização semivocalizada $[\mathrm{w}]$ para a lateral líquida em posição de coda, em especial porque é essa a variante usada majoritariamente pelos mais jovens. Hora (2006) apresenta dados que podem fazer-nos compreender o quão comum é esse processo fonológico. Das 3.703 ocorrências da lateral pós-vocálica analisadas pelo autor, a realização mais frequente é a semivocalização para [w], representando $84 \%$ dos dados, seguida pelo apagamento da lateral que representa $15,7 \%$ dos dados.

\subsection{Problemática e metodologia}

Uma vez que a criança, durante o processo de aquisição da linguagem, está exposta a processos fonéticos e fonológicos da língua materna, como é o caso da harmonia vocálica, do alçamento sem motivação aparente e a semivocalização da líquida lateral pós-vocálica, conforme apresentados na seção anterior, acreditamos que a aquisição da escrita possa sofrer influência desses processos. Com isso, esperamos encontrar em dados de aquisição da escrita grafias como 'mininu', 'piquena' e 'papeu' para 'menino', 'pequena' e 'papel'.

Neste trabalho, iremos além dessa influência, procurando investigar se há também, por parte da criança, uma estratégia de hipercorreção. Nesse sentido, podemos esperar uma escrita do tipo meneno, por exemplo, indicando uma hipercorreção do segundo 'i' da palavra para 'e', conforme seria esperado para a primeira vogal. Da mesma forma, se a criança associa o som 'u' com a letra 'l' em posição pós-vocálica ou com a letra 'o' em posição pretônica, é possível que ela escreva pedil para 'pediu' e boraco para 'buraco', por exemplo. Observe, entretanto, que são formas que não se apoiam na maneira como essas palavras são produzidas na língua oral, mas, sim, em generalizações feitas com base na fonologia da língua. A motivação de se trabalhar com esses contextos, em especial no alçamento ou harmonia de /o/ e a semivocalização de /1/, é justamente verificar se a criança está atenta aos contextos em que cada um ocorre. Veja que tanto o/o/ quanto o/1/ podem ter formas fonéticas bastante semelhantes, a vogal $[\mathrm{u}]$ para o primeiro e o glide $[\mathrm{w}]$ para $\mathrm{o}$ segundo. A hipercorreção poderá indicar se a criança está atenta a estes contextos: apesar de a realização fonética ser semelhante, o 'l' escrito ocorre em posição pós-vocálica ( $p a-$ pel, dedal), enquanto o 'o' ocorre em posição pretônica (boneca, colégio).

A fim de fazer essa checagem, fizemos uso de dados de escrita da $1^{\text {a }}$ até a $6^{\mathrm{a}}$ série do Ensino Fundamental I, provenientes do projeto E-Labore da Faculdade de Letras da 
Universidade Federal de Minas Gerais (CRISTÓFARO-SILVA et al., 2009). Levandose em conta apenas dados de hipercorreção, analisamos um total de 1.836 ocorrências, distribuídas da seguinte forma (uma vez que a harmonização vocálica e o alçamento sem motivação aparente produzem o mesmo resultado, [i] e [u], optamos por analisar esses dados em conjunto):

\begin{tabular}{l|c|c|c} 
& $\begin{array}{c}\text { Hipercorreção para 'e' } \\
(\text { minoria } \rightarrow \text { 'menoria') }\end{array}$ & $\begin{array}{c}\text { Hipercorreção para 'o' } \\
(\text { mulher } \rightarrow \text { 'moler') }\end{array}$ & $\begin{array}{c}\text { Hipercorreção para 'l' } \\
(\text { fugiu } \rightarrow \text { fugil })\end{array}$ \\
\hline $\begin{array}{l}\text { Harmonização vocálica } \\
\begin{array}{l}\text { Alçamento s/ motiva- } \\
\text { ção aparente }\end{array}\end{array}$ & 857 & 254 & - \\
\hline Semivocalização de $/ 1 /$ & - & - & 725 \\
\hline
\end{tabular}

Tabela 1. Distribuição dos dados analisados

Apesar de a harmonia vocálica e o alçamento vocálico sem motivação aparente afetarem apenas a pauta vocálica pretônica, os dados de hipercorreção de 'i' para 'e' (como biquini $\rightarrow$ 'bequini') e de 'u' para 'o' (como buraco $\rightarrow$ 'boraco') foram classificados quanto à posição tônica em que a vogal se encontra na palavra (pretônica, tônica ou pós-tônica). O intuito dessa classificação foi o de verificar se a criança está atenta à restrição prosódica dessas regras quando hipercorrige sua escrita.

Os resultados e a discussão serão apresentados na seção que segue.

\section{Resultados e discussão}

No Gráfico 1, abaixo, apresentamos os resultados, em números absolutos, para as hipercorreções de 'u' para 'o' encontradas nos dados de escrita. Observe que, apesar de ocorrerem hipercorreções nas pautas tônicas e pós-tônicas, como mostram os exemplos em (2) e (3) abaixo, é na posição pretônica (exemplos em (1)) que elas se mostram mais frequentes. Em relação ao avanço escolar, observamos um aumento de hipercorreções a partir da segunda série, período no qual a criança deve aumentar sua produção escrita, e um decréscimo a partir das séries finais. 
Gráfico 1. Hipercorreções de 'u' para 'o' $(n=508)$

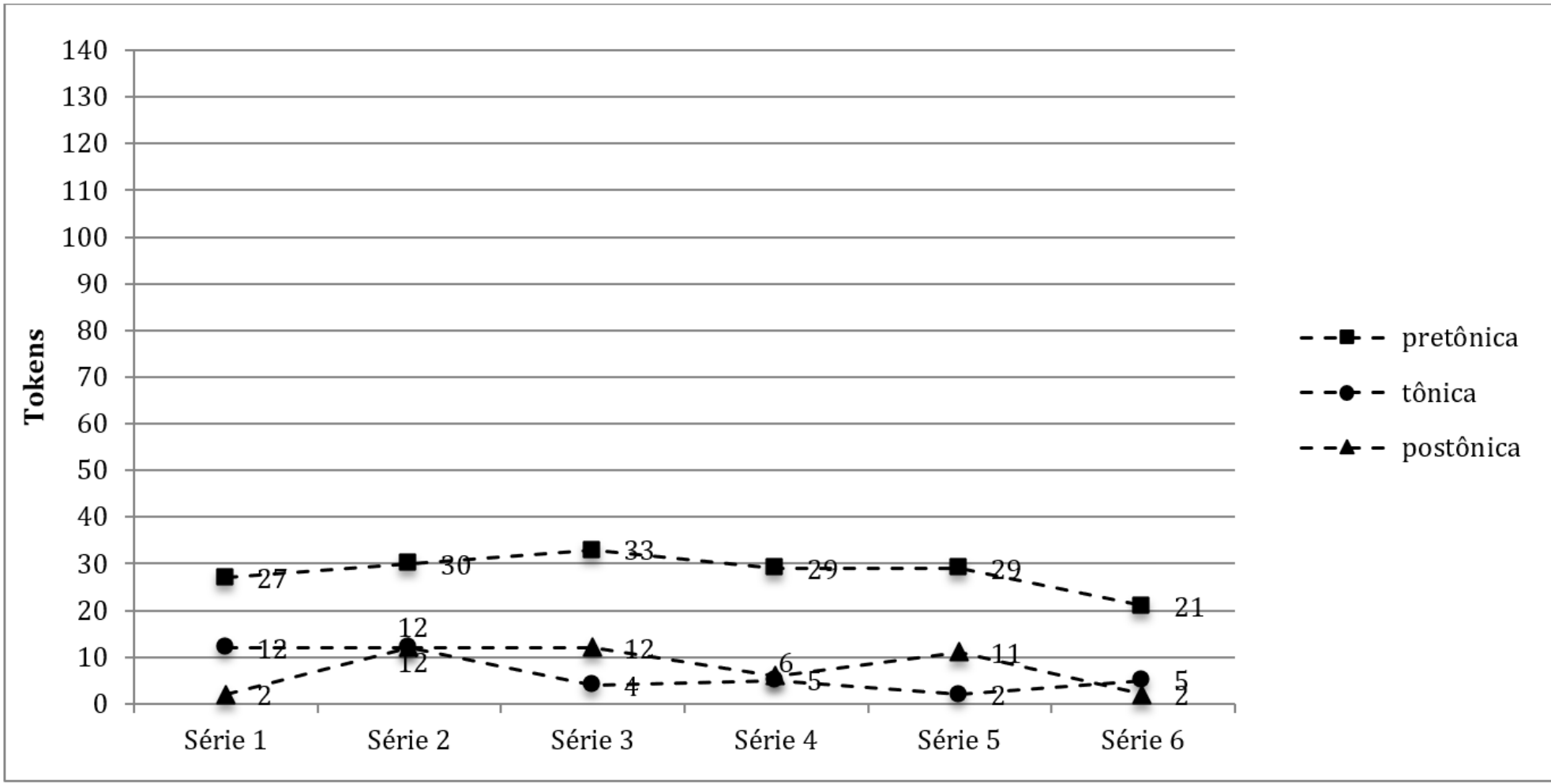

(1) posição pretônica
a. subir
$\rightarrow$ sobir
série 2
b. junina
$\rightarrow$ jonina
série 3
jonéna
c. churrasco $\rightarrow$ chorrasco série 6
d. futebol $\rightarrow$ fotbol série 5

(2) posição tônica
a. pulo
$\rightarrow$ polo
série 5
b. verdura $\rightarrow$ verdora
série 1
c. pontudo
$\rightarrow$ pontodo
série 1

(3) posição pós-tônica
a. título
$\rightarrow$ titolo
série 4
b. ônibus
$\rightarrow$ honibos
série 3
c. vírus
$\rightarrow$ veros
série 6

O fato de as hipercorreções ocorrerem mais frequentemente na posição pretônica pode ser tomado como evidência da sensibilidade da criança quanto à instabilidade dessa pauta em relação às posições tônicas e pós-tônicas. Tal diferença, entretanto, está mais acentuada nos resultados para as hipercorreções de 'i’ para 'e', conforme mostra o Gráfico 2 , que segue. Observe que, da mesma forma que para as hipercorreções de 'u', aqui também ocorrem hipercorreções nas posições tônica e pós-tônica (exemplos em (5) e em 
(6)), mas, diferentemente de 'u', o número de hipercorreções na pauta pretônica (exemplos em (4)) é consideravelmente maior do que nas outras pautas. Também, ao contrário de 'u', as hipercorreções de 'i' na pauta pretônica tendem a aumentar com o avanço esco-

Gráfico 2. Hipercorreções de 'i’ para 'e’' $(n=857)$

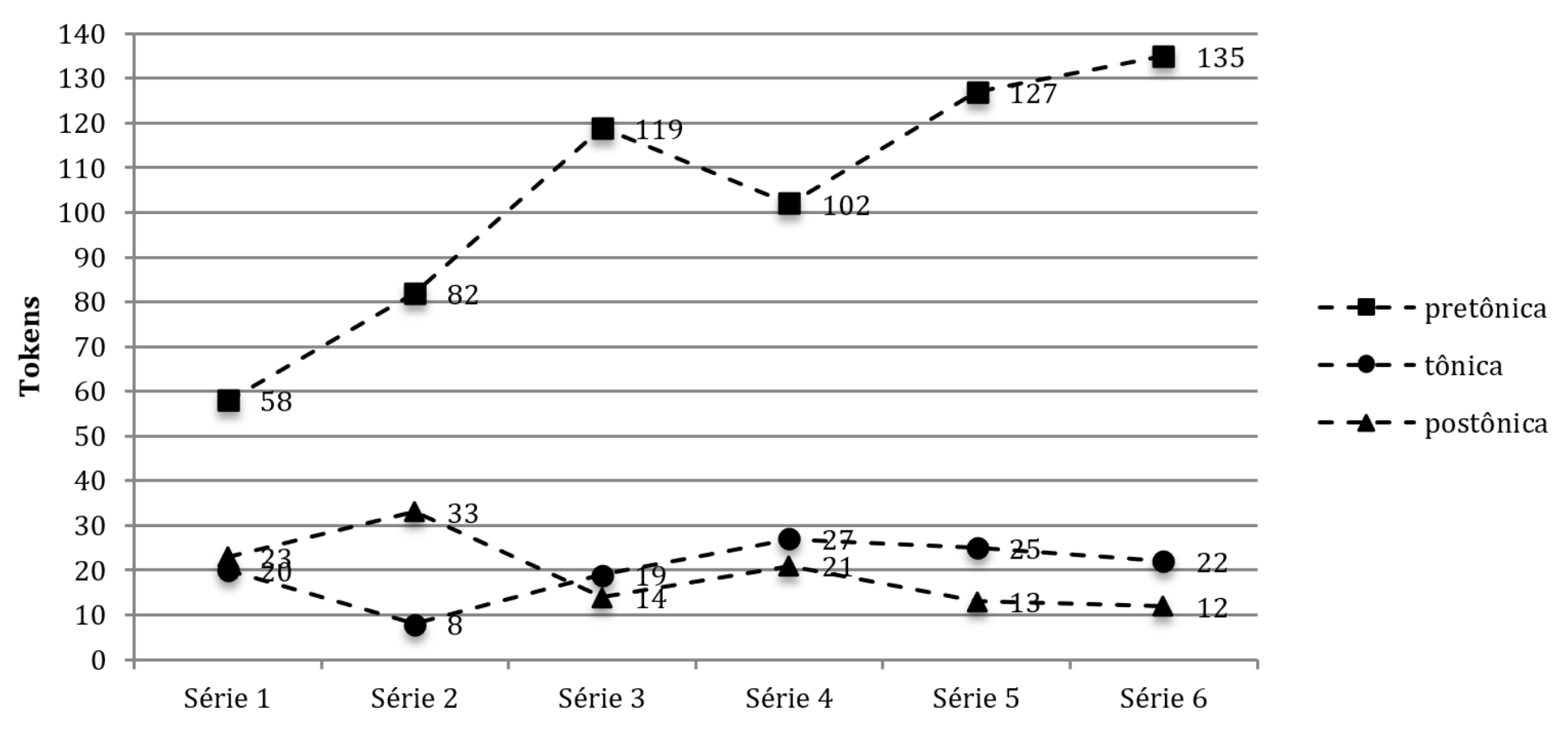

lar, enquanto as com a vogal 'u' tendem a diminuir.

(4) posição pretônica
a. biquín
$\rightarrow$ bequine
série 1
b. piscina $\rightarrow$ pesina
série 3
c. interessa $\rightarrow$ enteressa série 2
d. diferença $\rightarrow$ deferença série 4

(5) posição tônica
a. menina $\rightarrow$ menina série 5
b. precipício $\rightarrow$ precipécio série 6
c. polícia $\rightarrow$ polecia série 5

(6) posição pós-tônica
a. ótimo $\rightarrow$ ótemo série 4
b. príncipe $\rightarrow$ princepe série 2
c. hábito $\rightarrow$ habeto série 5

A diferença significativa entre a hipercorreção da labial 'u' e a da coronal 'i' pode corroborar o argumento de que somente a coronal /e/ seja, de fato, alvo do processo de harmonia vocálica do português brasileiro (cf. BOHN, 2015; CALLOU et al., 2002; 
YACOVENCO, 1993; entre outros). O fato de um segmento em determinada posição na palavra ser alvo de uma regra que, além de opcional, não atinge todos os contextos favoráveis a sua aplicação ${ }^{5}$, como vimos na seção acima, pode assegurar-lhe um estatuto instável na língua, pois essas características não permitem que o falante aplique a regra fonológica que rege a sua mudança de forma consistente. Uma vez que a instabilidade se mostrou mais acentuada nas hipercorreções da pretônica coronal, é possível que tomemos esse resultado como mais um indício de que apenas a pretônica 'e' seja alvo de harmonização no português brasileiro. Nesse caso, a criança estaria mais atenta ao estatuto da pretônica coronal /e/ e, por isso, produziria mais dados de hipercorreções de 'i' para 'e', como atestam os resultados.

No Gráfico 3, apresentamos os resultados para a hipercorreção da lateral pós-vocálica. Observamos um alto índice de hipercorreção em casos nos quais 'u' encontrava-se em ditongo final em contrapartida à posição medial. Uma vez que não consideramos nessa pesquisa as escritas corretas dessas palavras, não podemos concluir com esses resultados se, de fato, a criança está mais sensível à correção de 'l', e, consequentemente, à hipercorreção de 'u', na posição final de palavra. Para isso, teríamos que verificar a relação entre escritas corretas e erradas nesses contextos, o que foge do escopo desta pesquisa. Observamos, entretanto, que nos dados analisados há uma grande frequência de verbos conjugados na terceira pessoa do singular do pretérito perfeito, cuja desinência tende a ser um ditongo decrescente (parou, comeu, conseguiu) (46 ocorrências de não-verbos $X$ 446 ocorrências de verbos). Além da maior frequência de verbos nesse corpus, vale fazermos uma predição aqui: o fato de os ditongos decrescentes finais em verbos serem resultados de uma flexão verbal pode assegurar-lhes um estatuto mais produtivo do que aqueles que ocorrem em posição medial, fazendo com que uma regra que os afete seja mais facilmente generalizada across-the-board, ou seja, aplicada em todos os contextos linguísticos relevantes. Nesse sentido, a criança poderia estar criando uma regra de hipercorreção para todas as desinências verbais terminadas em ditongo decrescente com 'u. Além das hipercorreções afetando os ditongos decrescentes descritas acima, observamos também alguns casos em que a lateral pós-vocálica foi inserida após a grafia de um 'u', como mostram os exemplos em (8) abaixo. Das 33 ocorrências em que essa inserção ocorre, 28 foram em posição pretônica (como em hulmilde e fulturo, por exemplo) enquanto que 5 foram em posição tônica (como em estitulto para 'instituto' e samul para 'Samu', por exemplo). Por último, para todos os contextos em que houve hipercorreção

\footnotetext{
${ }^{5}$ Veja, por exemplo, que palavras como tecido e abertura, apesar de atender as condições linguísticas para a harmonização vocálica, não são realizadas como $t[i]$ cido e $a b[i]$ rtura.
} 
Gráfico 3. Hipercorreções de 'u' para 'l' $(n=857)$

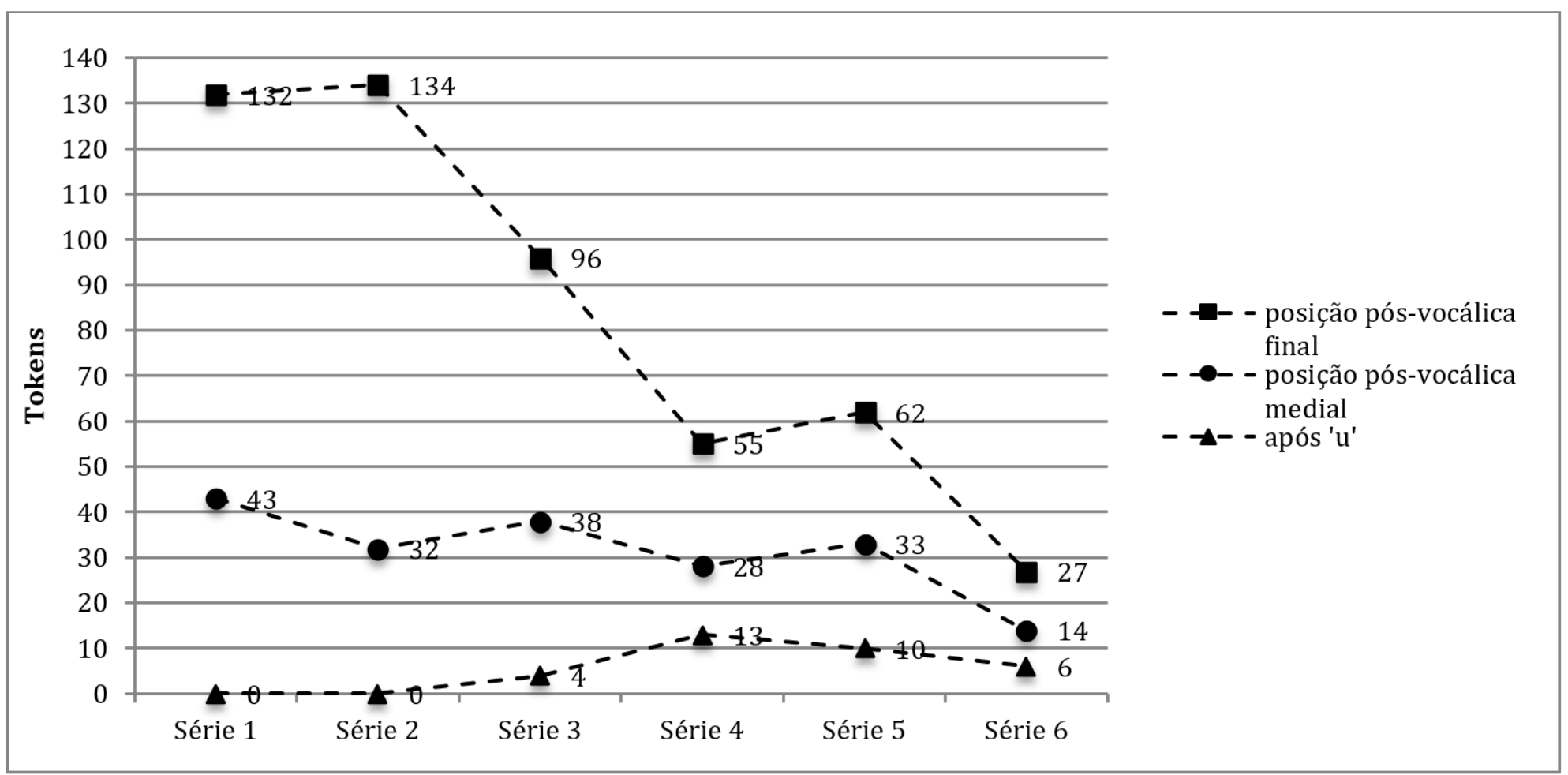

de 'u', observamos um decréscimo significativo com o avanço escolar, diferentemente do que ocorre com a hipercorreção de 'i' em posição pretônica.

(7) 'u’ pós-vocálico final
a. troféu
$\rightarrow$ trofel
série 5
b. tchau
$\rightarrow$ tial
série 2
c. viu
$\rightarrow$ vil
série 1
d. jogou
$\rightarrow$ jogol
série 5

(8) 'u' pós-vocálico medial
a. houve
$\rightarrow$ olve
série 5
b. ouro
$\rightarrow$ olro
série 3
c. caule $\rightarrow$ calle
série 2
d. saudades $\rightarrow$ saldades
série 4

(9) após 'u'
a. humilde $\rightarrow$ ulmilde série 5
b. futuro $\rightarrow$ fulturo série 4
c. escute $\rightarrow$ esculte série 5
d. viaduto $\rightarrow$ viadulto série 6

Em relação aos exemplos em (9), produções nas quais a criança acrescenta a lateral após ' 'u', a omissão da vogal resultaria na violação do filtro silábico do português: *l.mil. de, *fl.tu.ro, *es.cl.te, *vi.a.dl.to. Apesar de o /1/ poder ser núcleo silábico em algumas lín- 
guas, no português brasileiro apenas segmentos vocálicos estão licenciados a ocupar essa posição silábica. Uma violação desse tipo iria, portanto, de encontro ao que é permitido na língua e causaria estranhamento ao falante. Entendemos, portanto, que dados como os em (9) são resultantes de uma regra de hipercorreção, a de que [u] ou [w] fonéticos devem ser grafados como 'l', mas respeitam o filtro silábico da língua. Daí a redundância de 'u' seguido de 'l' na escrita.

\section{Considerações finais}

Neste artigo, procuramos buscar evidências de que a gramática fonológica do falante é atuante na aquisição do código escrito. Para isso, analisamos hipercorreções presentes em dados de escrita inicial com base em três fenômenos fonológicos do português brasileiro: a harmonização vocálica, o alçamento sem motivação aparente e a semivocalização da lateral pós-vocálica. Nossos resultados mostram que, em relação à harmonização e ao alçamento, (i) ocorrem um número maior de hipercorreções na pauta pretônica, o que coincide com o lócus desses processos da língua; e (ii) ocorrem mais hipercorreções com a vogal 'i', o que corrobora o argumento de que somente a vogal coronal é alvo de harmonização na língua, sendo o alçamento da labial /o/ resultado de uma motivação fonética apenas. Esses fatos revelam não só como as regras atuam na língua, mas também que a criança faz uso do seu conhecimento fonológico ao aprender o código escrito. Em relação à semivocalização da lateral pós-vocálica, vimos que as terminações verbais foram as mais afetadas pela hipercorreção, resultado de uma possível hipercorreção generalizada de uma operação morfológica produtiva na língua, a flexão verbal. Vimos também que, mesmo nas produções em que a hipercorreção foi generalizada para contextos além daqueles afetados pelos processos da língua, como é o caso de ulmilde e fulturo, nos quais há a inserção de um 'l' após um 'u' núcleo silábico, esses não violaram as restrições prosódicas e fonotáticas do português brasileiro. Esperamos ter mostrado com esses fatos que a gramática fonológica da criança opera ativamente na aquisição da escrita e que as trocas ortográficas são resultantes de hipóteses complexas e elaboradas por parte da criança, e não de meros lapsos de escrita.

Vale ressaltar ainda que, neste estudo, não foi possível acompanhar individualmente o desenvolvimento da escrita de cada criança devido à forma como os dados estão disponibilizados, mas acreditamos que tal acompanhamento seja um importante complemento para a análise que aqui se pretendeu fazer, pois poderá revelar as estratégias e trajetória de cada indivíduo, permitindo que mais comparações e generalizações sejam 
feitas.

\section{Referências}

ABAURRE, M. B. M. Horizontes e limites de um programa de investigação em aquisição da escrita. In: LAMPRECHT, R. R. (Org.) Aquisição de linguagem: questões e análises. Porto Alegre: EDIPUCRS, 1999. p. 167-186.

ADAMOLI, M. A. As diferentes grafias dos ditongos variáveis em textos de escrita inicial. Cadernos de Educação. v. 35, p. 303-322, 2010.

BATTISTI, E.; MORAS, V. T. A vocalização da consoante lateral em coda silábica em uma variedade de português brasileiro: análise sociolinguística em tempo real. Gragoatá, n. 40, p. 90-112, 2016.

BISOL, L. Harmonia vocálica: uma regra variável. Tese (Doutorado em Linguística) Faculdade de Letras. Universidade Federal do Rio de Janeiro, 1981.

. Ditongos derivados. D.E.L.T.A., v. 10, n. Especial, p. 123-140, 1994.

BOHN, G. P. Aquisição das vogais tônicas e pretônicas do português brasileiro. Tese (Doutorado em Linguística) - Faculdade de Filosofia, Letras e Ciências Humanas, Universidade de São Paulo, 2015.

CALLOU et al. A elevação das vogais pretônicas no português do Brasil: processo(s) de variação estável. Letras de Hoje, Porto Alegre: EDIPUCRS, v. 37, n. 1, 2002, p. 9-24.

CÂMARA JR., J. M. Estrutura da Lingua Portuguesa. 30. ed. Rio de Janeiro:

Vozes, 1999.

CASAGRANDE, G. P. B. Harmonização vocálica: análise variacionista em tempo real. Dissertação (Mestrado em Letras) - Faculdade de Letras, PUCRS, 2004.

CRISTÓFARO-SILVA, T. et al. Corpus do e-Labore (Laboratório Eletrônico de Oralidade e Escrita). Disponível em: www.projetoaspa.org/elabore.

CRISTÓFARO-SILVA, T.; GUIMARÃES, D. O. A aquisição da linguagem falada e escrita: o papel da consciência linguística. Letras de Hoje, v. 48, n. 3, p. 316-323, 2013.

CUNHA, A. P. N. A hipo e a hipersegmentação nos dados de aquisição da escrita: um estudo sobre a influência da prosódia. Dissertação (Mestrado em Educação) - Faculdade de Educação, Universidade Federal de Pelotas, 2004.

FERRERO, E.; TEBEROSKY, A. Psicogênese da língua escrita. Porto alegre: Artes Médicas, [1984] 1999.

GRECO, A. Alçamento de vogais médias pretônicas do português na oralidade de crianças de Belo Horizonte. Monografia (Trabalho de Conclusão de Curso) - Faculdade de Letras da Universidade Federal de Minas Gerais, 2009.

HORA, D. Variação fonológica: consoantes em coda silábica. In: TRAVAGLIA, L. C.

(Org.). Encontro na linguagem: estudos linguísticos e literários. Uberlândia: EDUFU, 
2006.

LAMPRECHT, R. (Org.). Aquisição fonológica do português - Perfil de desenvolvimento e subsídios para terapia. Porto Alegre: Artmed, 2004.

LEMLE, M. Guia Teórico do Alfabetizador. São Paulo: Ática, 1987.

LEMOS, F. A. P. Interferência da oralidade na escrita: o caso do registro ortográfico de $e$, i, o, u átonos. Letras de Hoje, Porto Alegre, v. 36, n. 3, p. 465-471, 2001.

MARGOTTI, F. W.; PINHO, A. J. A variação da lateral pós-vocálica /1/ no português do Brasil. Working papers em linguística, v. 11, n. 2, p. 67-88, 2011.

MIRANDA, A. R. M.; CUNHA, A. P. N. Indícios de reestruturação do conhecimento fonológico da criança em dados de reparo na escrita inicial. Letras de Hoje, v. 48, p. 334354, 2013.

MONARETTO, V.N. O. O alçamento das vogais médias pretônicas/e/e/o/sem motivação aparente: um estudo em tempo real. Fragmentum, n. 39, 2013.

NESPOR, M.; VOGEL, I. Prosodic phonology. Dordrecht: Foris, 1986.

SILVA, E. A. Alguns pontos sobre a (não) relação da fala com a escrita. In: CAVALCANTE et al. (Org.). Questões em aquisição da linguagem e psicolinguística - Aquisição de gêneros textuais e leitura. v. III. João Pessoa: Mídia gráfica e editora, 2016, p. 13-27.

SCHWINDT, L. C. S. Harmonia vocálica em dialetos do Sul do País: uma análise variacionista. Dissertação (Mestrado) - Faculdade de Letras, Pontifícia Universidade Católica do Rio Grande do Sul, 1995.

YACOVENCO L. C. As vogais médias pretônicas no falar culto carioca. Dissertação (Mestrado em Língua Portuguesa) - Faculdade de Letras, Universidade Federal do Rio de Janeiro, 1993.

Data de submissão: 19/07/2017

Data de aceite: $16 / 11 / 2017$ 